\title{
Green Growth as the Best Choice for Chinese Small and Medium Enterprises in Sustainable Development
}

\author{
Huili Wang (Corresponding author) \\ School of Foreign Languages, Dalian University of Technology \\ Dalian 116024, China \\ E-mail: hilarydut@gmail.com \\ Chunyou $\mathrm{Wu}$ \\ School of Management, Dalian University of Technology \\ Dalian116024, China \\ E-mail: wucy@dlut.edu.cn
}

Received: October 12, $2010 \quad$ Accepted: November 15, $2010 \quad$ doi:10.5539/ass.v7n5p81

The research was financed by National Natural Science Foundation of China No.71073016 (The Research on capacity-building pattern of the promotion of non-renewable resources efficiency in the life-cycle).

\begin{abstract}
It has been admitted that green growth is a focus for various international organizations. The paper aims to clarify the fact that green growth is the best choice for Chinese small and medium enterprises (SMEs) in sustainable development. Problems and opportunities in the sustainable development of SMEs are discussed. Finally, some feasible approaches to the green growth of Chinese SMEs are elaborated.
\end{abstract}

Keywords: Green growth, Small and medium enterprises, Sustainable development

\section{Introduction}

According to the UN organization Green Growth is defined as follows:

... a regional strategy for achieving sustainable development .... Green Growth advocates growth in GDP that maintains or restores environmental quality and ecological integrity, while meeting the needs of all people with the lowest possible environmental impacts. It is a strategy that seeks to maximize economic output while minimizing the ecological burdens. This new approach seeks to harmonize economic growth and environmental sustainability by promoting fundamental changes in the way societies produce and consume....

Mr. Wolfgang-Pape, member of the European Commission, said on the 'Low-carbon Development China Forum 2010: Road of New Energy Vehicles' held in Beijing on May 15th, 2010 that 99.1\% of the enterprises in Europe are small and medium-sized ones. Other documents show that the contribution rate of small and medium-sized enterprises (SMEs) in the European Commission is $57 \%$, the percentage and contribution rate of SMEs in America, Japan and Korea are also beyond $99 \%$ and $50 \%$. Hence the development of SMEs is of vital importance for all the nations.

Li Zibin, president of the Chinese Small and Medium-sized Enterprises Association, said on the National Joint Conference of Small and Medium-sized Enterprises Association held in Dandong, Liaoning on May 14th this year, that by the end of last year, the number of SMEs registered in the Department of Industry and Commerce in China is up to 10.23 million and takes up more than $99 \%$ of the total number of Chinese enterprises. The contribution of these enterprises is over $80 \%$ in the field of GDP and over $50 \%$ in tax revenue. They have also provided nearly $70 \%$ of the value of imports and exports and created around $80 \%$ of the jobs in cities and towns.

Although we have already seen the vigorous development of Chinese SMEs, there still remain some urgent problems. The Chinese Government has promulgated Opinions of the State Council on encouraging and guiding 
nongovernment investment to achieve sound development, which is designed to encourage and guide nongovernmental capital into industries and fields that are not forbidden by laws and regulations. Li Zibin believes this has provided more investment channels for the nongovernmental capital. The Chinese Government has unveiled many policies to support the development of SMEs in recent years, and the SMEs have also become an attracting power in Chinese economy.

\section{Bottlenecks in the sustainable development of SMEs in China}

\subsection{Bottlenecks in investment opportunity and environment}

In 'the interview of the responsible official of China National Development and Reform Commission about the Opinions of the State Council on encouraging and guiding nongovernment investment to achieve sound development (2010)', there is a definite answer to the question of "What difficulties and barriers are still disturbing the development of nongovernment investment?". These difficulties and barriers are mainly shown in four aspects. First, there are some barriers in entering the industry. Especially in those traditional monopolized industries and fields, there are still some "glazed doors" and "swing doors", which restrict the nongovernment investment from entry. Second, the financing difficulty has not been solved. Under the influence of the international financial crisis, bank credit is mainly given to those big projects and enterprises, which makes it harder for SMEs in financing. Third, the capacity of nongovernment investment needs improving. The investment transformation and promotion pace of private enterprises needs to be speeded up, innovation ability be improved and management skill be promoted. Fourth, the policy environment of nongovernment investment needs to be ameliorated continuously and the service system also should be perfected day by day.

\subsection{High energy-consumption pollution, low technology and productivity in nongovernmental economy}

In response to 'the objective needs in adapting the economy structure adjustment and economic globalization development', there is still much room for improvement for the nongovernment investment in investment structure. According to statistics, its investment fields are mainly those 'downstream industries', like wholesale business and retail trade, accommodation and restaurants, neighborhood service and other service industries, manufacturing, etc. At the same time, quite a number of industries of high energy-consuming and pollution while low technology and productivity exist in nongovernmental economy. The task to transform the development mode of private enterprises is of great importance and urgency.

\subsection{Insufficient "Greening" capability}

SMEs are low in the capacity of technology innovation and application. They have not realized the vital importance of increasing the investment in research and promoting their independent innovation capacity, and they are weak in action. Hence, SMEs do not possess the sufficient capability to master the core technology and commercialize the technological results independently.

The most critical step is to improve their understanding and the capacity of "Greening" and "Low Carbon", especially the most welcoming Green Economy, Low Carbon Economy and Circular Economy. Sustainable development could never be achieved if the opportunity is not seized.

\section{SMEs "green growth" opportunities in China}

Japan's Basic Law for SMEs, is both the creedal regulation for the development of SMEs and the overall basis for the current policy and policy management (Piao, 2000). The U.S. Financial Assistance Act for SMEs clarifies using "comprehensive free competition" to "release energy from market supply and demand and remove barriers to entry into the market". "Taking the innovation and development as the motive and taking high-tech industry as the core" are strategic goals that have long been upheld by the U.S. SMEs (Xie, 2008). Promising high-tech SMES has been explicitly identified as the target that the United States focuses to support in the future. The U.S. SMEs play an important role in promoting the innovation of new technology development and production growth. SMEs are engines for the U.S. economy and the strongest economic entities. In order to construct "comprehensive competitive growth mode", the US greatly widened the industry domain of SMEs and the scope of industry. In the field of high-tech domains such as information technology, biological technology or other industries such as petroleum processing, airfreight and sea freight, the SMEs play a vital role.

The European Commission (EU) (2010) has launched a new comprehensive strategy for green growth, innovation and jobs. The objective is to get Europe out of crisis and prepare the EU economy for the next decade and the long-term challenges of sustainable growth, resources efficiency and aging. Green growth is an important element of the 2020 Strategy. Besides, EU provides a highly international platform for SMEs. To comply with the world trend of growth of SMEs and quicker, stronger participation in international competition, the European SMEs take the principles of both manufacturing and service industries as of equal importance in 
order to effectively adjust the industrial structure to promote economic growth and to increase employment opportunities.

Since the 1980s, South Korea released a SMEs Start-Law and a series of policies and regulations to support SMEs development. At the same time, South Korea has also taken corresponding measures in financial aspects. In addition, the South Korean government adopted a series of measures to support the establishment of the enterprises, including simplifying construction procedures, carrying out one-stop service system to save time and costs (Xie, 2008). The South Korean government gave full play to market mechanisms and at the same time, the government also established a strong government support system, including financial support, technical support, organizational support and business support, etc. Therefore, South Korea's SMEs play an increasingly important role.

In China, "The key points by State Council Office concerning encouragement with guidance for the healthy development of the private investment", issued by the state (2010) No.13 and "Opinions of the State Council on encouraging and guiding nongovernment investment to achieve sound development" on July $26^{\text {th }}$ are taken as the latest and most groundbreaking support documents to stimulate the development of SMEs.

\section{Feasible approaches to the green growth of Chinese SMEs}

The fashion icon of sustainable development of enterprises is 'green happiness enterprise', with three aspects of 'efficiency, innovation, green' sustained competitiveness as an assessment index of happiness entities.

To meet the opportunities and challenges faced by sustainable development of SMEs, feasible approaches to the green growth of SMEs are as follows.

\subsection{To seize the opportunity}

The experience that the development of SMEs is supported by governments in the world tells us that the development of SMEs is the cornerstone of national stability to avoid risks, to provide employment opportunities and promote the sustainable development.

Currently, 'the key points by State Council Office concerning encouragement with guidance for the healthy development of the private investment' introduced by China provides the most clear-cut guarantee for SMEs' sustainable development or green growth on the aspect of environment and policy, including 'to encourage and guide private capital to access into industries and fields that laws and regulations do not explicitly prohibit'.

\subsection{Initiative to enhance the "greening" and "low-carbon" capability}

Capability building is of particular significance to accelerate the green growth. SMEs can actively focus on improving the green and energy efficient technology, achieving sustainable development.

\subsection{Active participation in international competition}

SMEs can learn from other countries that have a lead in green growth, such as Korea, Japan, the United States, France Singapore so that they can increase their competiveness in the international market.

4.4 Creation of the best development platform as "human resource is the first resource"

As human resource is the first resource, so the awareness of the green growth should be increased. SMEs can spend some time and energy educating their stakeholders including employees and customers on the great importance of green growth so that more people can do something from themselves, thus increasing the efficiency of green growth.

\subsection{Promotion of eco-innovation}

According to the OECD (2009) definition, 'eco innovation' is distinguished from other kinds of innovation by the following characteristics:

1) Eco-innovation represents innovation that results in a reduction of environmental impact, no matter whether that effect is intended or not.

2) The scope of eco-innovation may go beyond the conventional organizational boundaries of the innovating organization and involve broader social arrangements that trigger changes in existing socio-cultural norms and institutional structures.

Eco-innovation is essential to ensure future economic growth and employment globally as well as to respond to today's major societal challenges, particularly environmental (See Figure 1). SMEs have a crucial place in eco-innovation, both as innovators and as recipients of green technologies. Their creativity and dynamism can play a key role in developing the environmental technologies and services necessary to bridge the gap between economic development and environmental sustainability. 


\section{Conclusion}

Green growth is a strategy for promoting economic growth with the goal of adding an ecological quality to existing economic processes and creating additional jobs and income opportunities with a minimal environmental burden. Green growth can be taken as the best choice for Chinese small and medium enterprises in sustainable development. In order to promote green growth Chinese small and medium enterprises, five points can be taken into account. The first point is to seize the opportunity; the second is to exercise SMEs' initiative to enhance the 'greening' and 'low-carbon' capability; the third is to take active participation in international competition to increase competitiveness; the fourth is to establish the best development platform as 'human resource is the first resource'; the last is to promote eco-innovation. The authors believe that these five points can help SMEs to enhance their green growth.

\section{References}

ETAP (Environmental Technologies Action Plan) Newsletter, 2010, 18:1.

GTZ. (2010). Sustainable Economic Development Discussion paper-Green growth. [Online] Available: http://www.enterprise-development.org (March, 2010).

OECD. (2009). Sustainable Manufacturing and Eco-innovation: Framework, Practices and Measurement-Eco-Innovation, Synthesis Report. [Online] Available: http://www.oecd.org/dataoecd/15/58/43423689.pdf. (Nov. 15, 2010).

OECD. (2010). Green growth and eco-innovation. [Online] Available: http://www.oecd.org/document/37/0,3343,en_2649_34173_40695077_1_1_1_1,00.html. (Nov. 15, 2010).

Opinions of the State Council on encouraging and guiding nongovernment investment to achieve sound development, State Council of the People's Republic of China. [Online] Available: http://www.gov.cn/zwgk/2010-05/13/content_1605218.htm (May 13, 2010).

Piao X. (2000). Implications of Japan's Basic Law for SMEs in China. DongJiang Journal, 17(3): 54-60.

Xie X., (2008). Road to SMEs-Internationalization of European Commission. [Online] Available: http://www.chinareform.org.cn/cirdbbs (Oct. 21, 2008).

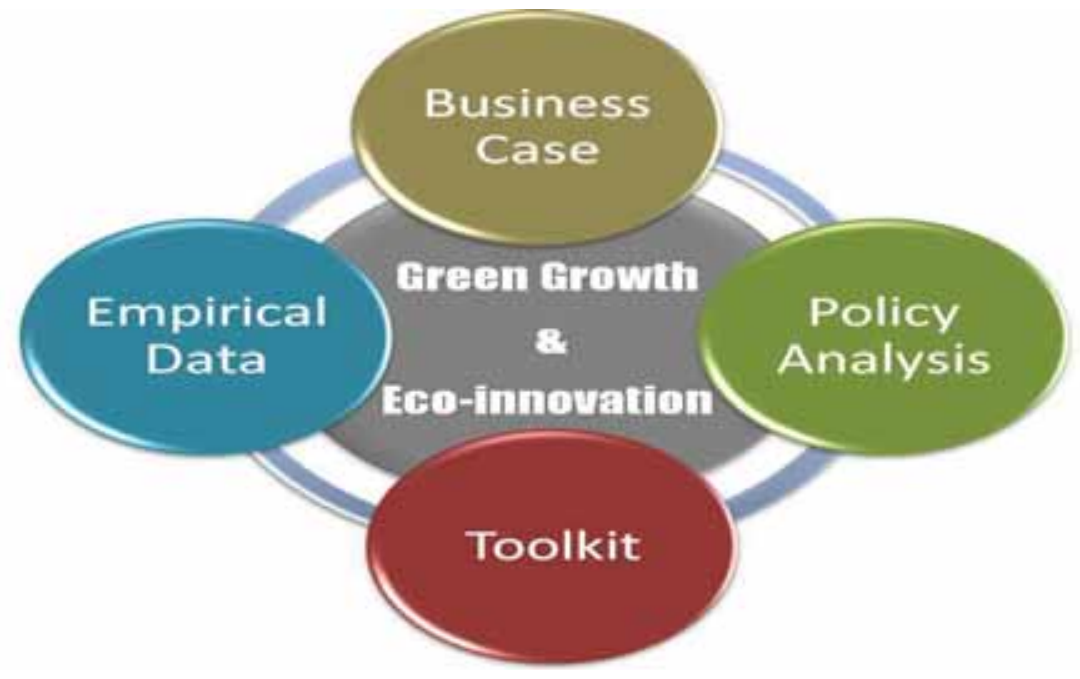

Figure 1. OECD green growth strategy 